\title{
Mega-Volume Fat Transplantation to the Breast and Buttocks: A New Surgical Technique That Brings New Anesthetic Challenges
}

\author{
Alexander D. Shapeton', Michael Semenovski², Daniel Del Vecchio ${ }^{3}$ \\ ${ }^{1}$ Department of Anesthesia, Critical Care and Pain Medicine, Beth Israel Deaconess Medical Center, \\ Boston, USA \\ ${ }^{2}$ Department of Anesthesiology \& Pain Medicine, St. Elizabeth's Medical Center, Boston, USA \\ ${ }^{3}$ Department of Surgery, St. Elizabeth's Medical Center, Brighton, USA \\ Email: ashapeton@bidmc.harvard.edu
}

Received 9 August 2014; revised 22 September 2014; accepted 23 October 2014

Copyright @ 2014 by authors and Scientific Research Publishing Inc.

This work is licensed under the Creative Commons Attribution International License (CC BY). http://creativecommons.org/licenses/by/4.0/

c) (i) Open Access

\begin{abstract}
Objective: Autologous fat-grafting for the purpose of breast augmentation has gained widespread acceptance as a viable and safe alternative to classical breast implant procedures and has recently been successfully applied to buttock augmentation. Due to the numerous patient re-positionings and widely variable OR time, these procedures present unique challenges for anesthesiologists. Our goal is to discuss the current surgical methods, anesthetic methods, risks and benefits of this procedure. Methods: This is a retrospective cohort study in the setting of the operating room. Twenty-nine consecutive cases of mega-volume fat transplantation, defined as $>300$ cc to an individual site, performed by one surgeon, were reviewed. Age, Body Mass Index, total fat injected, total operating room time, maximum intraoperative temperature, minimum intraoperative and temperature were measured. RESULTS: Our procedure has enjoyed a $100 \%$ patient satisfaction rate. Analysis reveals high variability in age (21 - 57), total fat injected (200 cc - $1990 \mathrm{cc})$, patient Body Mass Index (18.8 - 42.2) and total operating room time (1:23:00 - 6:14:00) for our procedures. There were no instances of major complications in this cohort. Conclusions: Autologous fat transplantation for the purposes of breast and buttock augmentation is an emerging technique that shows great promise and high patient satisfaction, but providing unique challenges for anesthesiologists and surgeons.
\end{abstract}

\section{Keywords}

Breast Augmentation, Buttock Augmentation, Tumescent, Clinical Anesthesia, Plastic

How to cite this paper: Shapeton, A.D., Semenovski, M. and Del Vecchio, D. (2014) Mega-Volume Fat Transplantation to the Breast and Buttocks: A New Surgical Technique That Brings New Anesthetic Challenges. Open Journal of Anesthesiology, 4, 254-262. http://dx.doi.org/10.4236/ojanes.2014.410038 


\section{Introduction}

Since the inception of breast augmentation 50 years ago and the discovery of liposuction 30 years ago, both procedures have eclipsed more classical procedures to become among the top five most performed procedures in all of plastic surgery [1]. Autologous fat grafting for the purpose of breast augmentation has gained widespread acceptance as a viable and safe alternative to classical breast implant procedures. Recently, autologous fat grafting has also been successfully applied to buttock augmentation. In 2009 the ASPS Fat Graft Task Force, created to determine the appropriate applications, risks and outcomes of fat grafting, published their review of the literature, in which they concluded that fat grafting can be used for breast augmentation [2]. The ASPS Fat Graft Task Force also mentions that there are currently no standards of practice for the procedure, and results/outcomes may be significantly surgeon-dependent. Recent data suggest that patients have been very satisfied with the results of both breast and buttock augmentations performed with fat grafting; a prospective study of gluteal augmentation reported a 93\% satisfaction rating of "good" or better in their 351 patient cohort [3], and a review of the breast literature also yielded largely positive satisfaction data [4].

Autologous mega-volume fat transplantation for breast and buttock augmentation, like any new procedure in surgery, is performed by a variety of surgeons with a wide range of expertise and technical strategies. We define mega-volume fat grafting as injecting over 300 cc to a given area, e.g. 300 cc per breast. Due to the numerous patient re-positionings and widely variable total OR times of these procedures, they represent unique challenges for anesthesiologists. Longer procedures, completely exposed patients, multiple re-positionings, large volumes of fat injected in the area of large veins, and the liberal use of local anestheticsall present a set of new and unique risks requiring careful anesthesia management.

Based on the continued success and popularity of breast augmentation and the recent rise in popularity of gluteal augmentation, the need for techniques that cater to individual preferences has never been greater. Autologous lipo-grafting is thus a viable alternative to standard implantation, because it provides excellent aesthetic results while minimizing negative outcomes.

The purpose of the present communication is to analyze our anesthetic experience with mega-volume fat transplantation patients at Saint Elizabeth's Medical Center, to categorize the potential risks of these procedures and to make recommendations for proper anesthetic care.

\section{Materials and Methods}

\subsection{Anesthetic Methods}

This study was approved by Human Research Committee of St. Elizabeth's Medical Center. After providing general written informed consent, 29 female patients (ASA physical status I-II) aged 21 to 57 years were scheduled for a procedure of a large-volume fat transplantation for breast and/or buttock augmentations which was performed by the same surgeon at ourinstitution. Breast and buttock augmentation are first and foremost elective procedures. As such, maximal patient comfort is a priority and a goal before, during and after each procedure. The patient's experience while having an elective cosmetic procedure done is essential, because it may influence their satisfaction with the end result. These procedures require the patient to be largely exposed throughout, and due to the numerous re-positionings and need for access to the thighs, buttocks, breasts and abdomen, it is difficult to rely solely on a heating apparatus like a Bair-Hugger, which we used in $90 \%$ of our cases. In patients expected to have shorter procedures who have initial temperatures above $37^{\circ} \mathrm{C}$, the Bair-Hugger is not always employed. Taking the patient's comfort into account, the operating room is always kept between $26^{\circ} \mathrm{C}$ and $28^{\circ} \mathrm{C}$, which leads to an average intra-operative patient temperature of $36.1^{\circ} \mathrm{C}$. Although AORN recommends that $\mathrm{OR}$ temperatures remain in the range of $20^{\circ} \mathrm{C}$ to $23^{\circ} \mathrm{C}$ [5], due to the patient's exposure for extended periods of time, higher temperatures, as often seen in pediatric burn surgery, are warranted [6].

Whether done on the breasts or buttocks, the procedure begins with a standing preparation of the entire body (excluding head and neck) using antiseptic solution, which is administered by the operating surgeon. Prior to entering operating room a small bore extension set was attached to the intravenous catheter so that the intraven- 
ous tubing can be easily disconnected from the patient. The IV is clamped to the patient's arm this is done in order to prevent the patient from tripping over it while the antiseptic solution is being applied. After application of antiseptic solution, patient is positioned on sterile sheets. Since the patient must be able to stand on their own during this preparation, the preoperative use of sedatives such as midazolam in the holding area should be avoided (Figure 1).

As soon as the patient has been completely prepped, and is on the operating table, $2 \mathrm{mg}$ of midazolam is administered intravenously as an anxiolytic and amnestic. Pre-oxygenation with $\mathrm{O}_{2}$ by mask is then performed while all of the appropriate monitors are applied for the procedure. As soon as all ASA standard monitors are on and connected, we administer between 100 and $250 \mathrm{mcg}(2-3 \mathrm{mcg} / \mathrm{kg}$ ) of fentanyl. Depending on the weight of the patient (our average patient BMI was 24.77), we then proceed to administer between $100 \mathrm{mg}$ and $200 \mathrm{mg}$ ( 2 $2.5 \mathrm{mg} / \mathrm{kg}$ ) of propofol as our primary induction agent. Simultaneously we administer between $40 \mathrm{mg}$ and $60 \mathrm{mg}$ $(0.6-0.8 \mathrm{mg} / \mathrm{kg}$ ) of rocuronium in order to facilitate direct laryngoscopy (DL). We do not re-dose the rocuronium in the vast majority of our cases, since muscle paralysis is not essential in what is mostly a subcutaneous surgery. The patient's eyes are then lubricated and taped shut. The DL is performed using a MAC- 3 or Miller- 2 blade in approximately 95\% of our procedures, routinely using a 7.0 Endotracheal Tube (ETT) followed by placement of an Orogastric (OG) Tube and OG temperature probe. We occasionally employ a Glidescope for small or questionable airway openings. Endotracheal intubation is employed for our patients because the liposuction and grafting procedures require significant movement and re-positioning of the patient over a long intraoperative time (average 178.3 minutes) and the procedure effectively secures the airway.

In about $90 \%$ of our cases we use $\mathrm{O}_{2}$-Air mixture with $\mathrm{ET}^{-\mathrm{FiO}_{2}}$ of $60 \%-80 \%$ together with Desflurane $6.6 \%$ 7.5\%. In most cases this correlates with a Bispectral (BIS) monitor index of 40 - 50 and maintains the patient anesthetized. In the other $10 \%$ of patients who report smoking or have active asthma symptoms, we instead opt for Sevoflurane as it is somewhat less irritating to the airway compared to Desflurane [7]. When using Desflurane or Sevoflurane, in most of our cases we aim for a MAC of 1.1 - 1.3 to keep a good depth of anesthesia. We generally try to avoid using Nitrous Oxide $\left(\mathrm{N}_{2} \mathrm{O}\right)$ during these procedures because of the increased risk of postoperative nausea and vomiting (PONV) associated with its use. Avoidance of $\mathrm{N}_{2} \mathrm{O}$ is especially important becauseour patients are largely female and receive opioid analgesia and volatile gas anesthesia, all factors that give them significant PONV risk [8] [9]. Additionally, $\mathrm{N}_{2} \mathrm{O}$ is known to have an additive effect on increasing PONV when given with opioids in females. We administer $4 \mathrm{mg}$ of ondansetron and $4 \mathrm{mg}$ of dexamethasone 1 - 2 hours into the operation, which have previously been found to significantly decrease the risk of PONV in plastic surgery patients [10]. A Scopolamine patch $1.5 \mathrm{mg}$ is additionally used in most cases where the patient has a significant history of PONV. The BIS is maintained between 40 and 55 at all times, a level that has been associated with improved post-operative recovery from relatively deep anesthesia and diminished incidence of intra-operative patient recall [11]. Additionally, when necessary, we elect to use medications such as ephedrine (intermit-

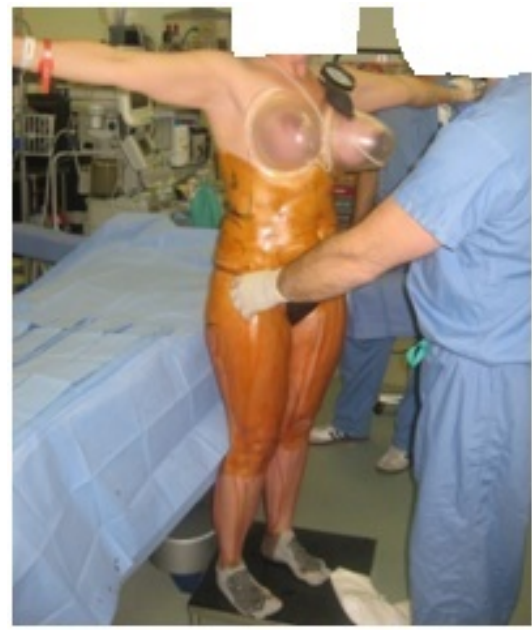

(a)

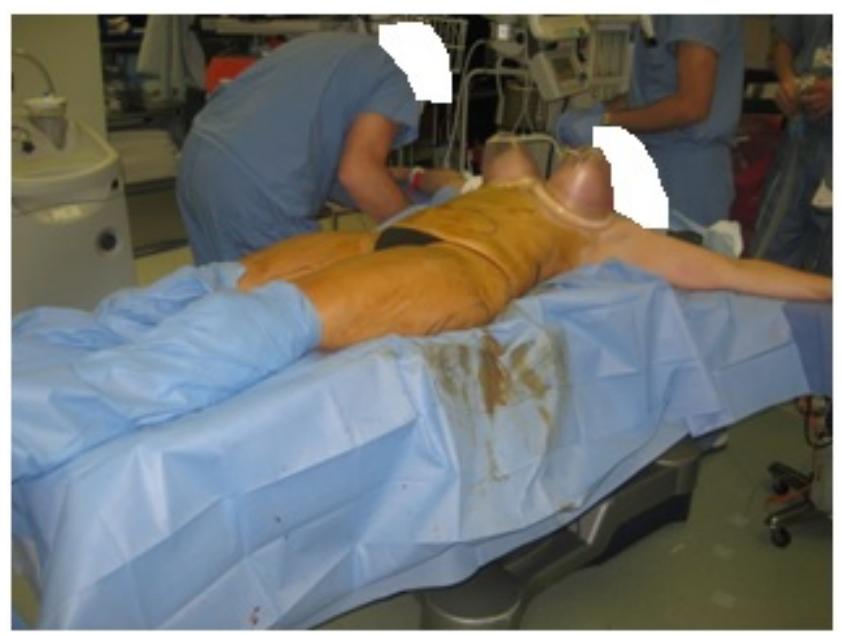

(b)

Figure 1. (a) Standing prep for mega-volume fat transplantation to the breast; (b) Sedation is to be avoided until the patient is supine on the OR table. 
tent 5 - 10 mg IV) or phenylephrine (intermittent 40 - 120 mcg IV) intra-operatively to maintain mean arterial pressure (MAP) above 55 - 60 (36.7\% of cases). Since approximately 95\% of our patients are scheduled to go home the day of their operation, we try to avoid the use of long-lasting narcotics and instead administer fentanyl as our narcotic of choice for post-operative pain control to maintain VAS (visual analog score) below 3 - 4 out of 10 in PACU area.

\subsection{Surgical Methods}

After the induction of anesthesia and placement of an endotracheal tube, the patient is essentially exposed from the neck to the knees. Venous compression boots are placed in the calf region, covered with sterile drapes, and remain in the surgical field. Tumescent solution, consisting of $30 \mathrm{~mL}$ of $1 \%$ lidocaine with epinephrine 1/100,000, is instilled into all areas where liposuction is to be performed. Liposuction is the initial phase of mega-volume fat transplantation, during which fat is harvested and stored in sterile canisters on the surgical field. Volumes of tumescent solution ranging from $2 \mathrm{~L}$ to $8 \mathrm{~L}$ are routinely used. Once the donor areas are completely tumesced, liposuction is performed using a $3-4 \mathrm{~mm}$ multi-hole cannula. Once the fat is harvested into canisters, it is then further processed by centrifugation to dehydrate the fat and to remove unwanted blood in crystalloid. The fat is theninjected into the breast or buttock using a 14 gauge blunt tip cannulas. Access to the subcutaneous space is obtained via a small 14 gage needle stick. Volumes ranging from $200 \mathrm{~mL}$ to $1300 \mathrm{~mL}$ are routinely used. In the breast, volumes range from $200 \mathrm{~mL}$ to $700 \mathrm{~mL}$; in the buttock, which has a larger capacity and requires a greater volume of augmentation, volumes range from $500 \mathrm{~mL}$ to $1300 \mathrm{~mL}$ of fat (Figure 2).

In breast augmentation, the entire procedure can be performed while the patient is in the supine position. In buttock augmentation, the patient must be placed directly prone on the operative table in order to facilitate aesthetic contouring and shaping of the buttock region. Following these procedures, patients must be placed in a compression garment to reduce the risk of edema and postoperative hemorrhage.

\subsection{Anesthesia Metrics Recorded}

Age, tumescent volume, BMI, OR time, intra-operative temperature minimum, intra-operative temperature maximum, volume of fat removed, volume of fat injected, major complications.

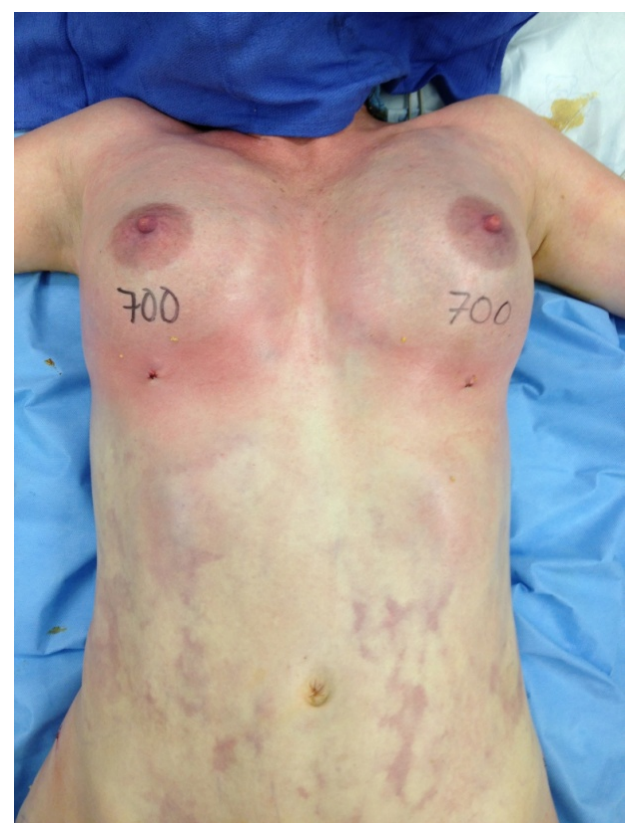

(a)

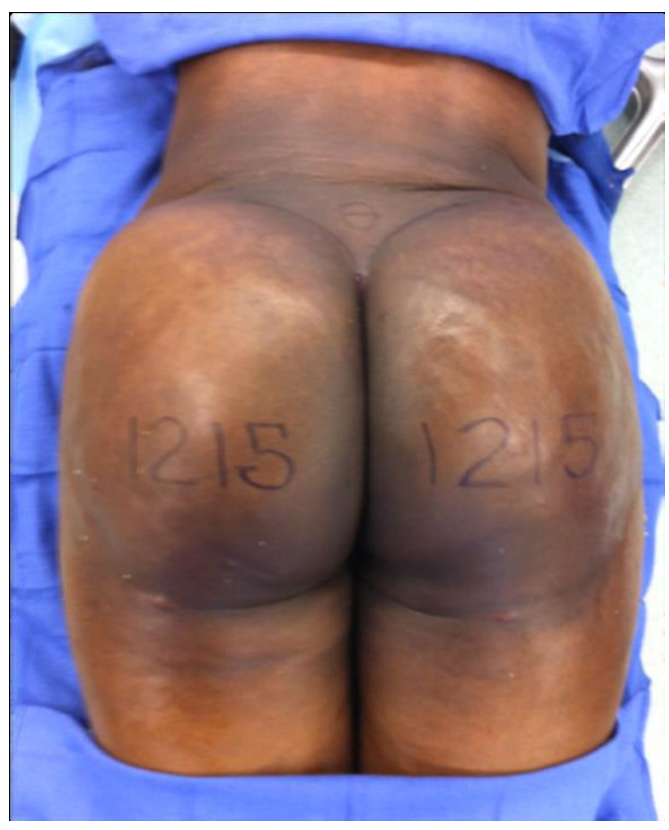

(b)

Figure 2. Volumes of fat transplanted in the breast (a) range from 200 - $700 \mathrm{cc}$, while those in the buttock range 500 - 1300 cc. Note that the patient on the right is in the full prone position, which requires intra-operative flipping on the OR table. 


\section{Results}

Patient age ranged from 21 years to 57 years with mean age 37.20 and SD $=9.95$. BMI also ranged dramatically from 18.8 to 42.2 with mean 24.74 and $\mathrm{SD}=5.02$. OR time ranged from 83 to 374 minutes with mean 178.3 minutes and $\mathrm{SD}=60.3$. Patient temperature maximum ranged from $35.3^{\circ} \mathrm{C}$ to $37.2^{\circ} \mathrm{C}$ with mean $36.1^{\circ} \mathrm{C}$ and $\mathrm{SD}$ $=0.55$. Patient temperature minimum ranged from $33.2^{\circ} \mathrm{C}$ to $36^{\circ} \mathrm{C}$ with mean $34.6^{\circ} \mathrm{C}$ and $\mathrm{SD}=0.67$. Fat removed ranged from 1000 to 7000 cc with mean 4379 cc and SD $=1192$. Fat injected ranged from 200 to 1990 cc with mean $1154 \mathrm{cc}$ and SD = 400. Tumescent solution used ranged from 1000 to $9000 \mathrm{cc}$ with mean $6580 \mathrm{cc}$ and SD = 2001 (Table 1). Patients who are older and patients who are obese are candidates for this procedure but are expected to be at higher risk of complications. Meanwhile, patients with lower BMIs have less insulation and are at higher risk for hypothermia. The maximum temperature in all patients ranged from $35.3^{\circ} \mathrm{C}$ to $37.2^{\circ} \mathrm{C}$. Considering that there were some patients whose maximum temperature was only $35.3^{\circ} \mathrm{C}$, an argument could be made for pre-warming certain patients in the holding area or that upon their arrival in the operating room. Although the goal is to have the room temperature at $27^{\circ} \mathrm{C}$ to $30^{\circ} \mathrm{C}$ for every case, this is sometimes not possible due to the logistics of the operating room.

We also compared the five patients with the lowest minimum intraoperative temperatures to the five patients with the highest intraoperative minimum temperatures (Table 2). In the high minimum (HM) group, the temperatures ranged between $35.0^{\circ} \mathrm{C}$ and $36.0^{\circ} \mathrm{C}$ with mean $35.3^{\circ} \mathrm{C}$ and $\mathrm{SD}=0.38$, while in the low minimum (LM) group the temperatures ranged from $33.2^{\circ} \mathrm{C}$ to $34.0^{\circ} \mathrm{C}$ with mean $33.7^{\circ} \mathrm{C}$ and $\mathrm{SD}=0.31$. When the two groups were compared, BMI of those in HM group ranged from 18.8 to 42.2 with mean 27.14 and SD = 9.89, while those in LM group ranged from 20.8 to 29.6 with mean 25.1 and SD $=4.9$. Though the small size of our sample limits our ability to obtain statistically significant data, it appears as though there may be a correlation between higher minimum intraoperative temperatures and higher BMI. Intuitively, it stands to reason that a patient with a higher BMI and likely higher overall adiposity may maintain a higher core body temperature due to the adipose tissue's insulatory effect on the body. Representative clinical results are shown in Figure 3 and Figure 4.

\section{Complications}

There were no cases of major hemorrhage leading to significant hypotension, fat or pulmonary embolism, hypothermia leading to cardiac arrhythmia or other major organ system pathology, or adverse reactions to medication, including lidocaine toxicity. Though vasopressors were used during $36.7 \%$ of our cases, there were no episodes of hypotension resistant to small dose vasopressors, and we attribute the presence of intermittent minor intra-operative hypotension to our use of volatile anesthetic gases.

Table 1. Summary data from 29 consecutive cases of mega-volume fat transplantation.

\begin{tabular}{ccccc}
\hline & Minimum & Maximum & Mean & Standard Deviation \\
\hline Age (Years) & 21 & 57 & 37.20 & 9.95 \\
BMI & 18.8 & 42.2 & 24.74 & 5.02 \\
OR time & $1: 23: 00$ & $6: 14: 00$ & $2: 59: 48$ & $1: 00: 18$ \\
Temperature Max ( $\left.{ }^{\circ} \mathbf{C}\right)$ & 35.3 & 37.2 & 36.1 & 0.55 \\
Temperature Min ( $\left.{ }^{\circ} \mathbf{C}\right)$ & 33.2 & 36 & 34.6 & 0.67 \\
Fat Removed (cc) & 1000 & 7000 & 4379 & 1192 \\
Fat Injected (cc) & 200 & 1990 & 1154 & 400 \\
Tumescent Used (cc) & 1000 & 9000 & 6580 & 2001 \\
\hline
\end{tabular}

Table 2. Summary data comparing the two $(n=5)$ groups of patients with the highest and lowest minimum temperatures.

\begin{tabular}{lcccccccc}
\hline & $\begin{array}{c}\text { Minimum } \\
\text { Temp }\end{array}$ & $\begin{array}{c}\text { Maximum } \\
\text { Temp }\end{array}$ & $\begin{array}{c}\text { Mean } \\
\text { Temp }\end{array}$ & $\begin{array}{c}\text { Standard } \\
\text { Deviation }\end{array}$ & $\begin{array}{c}\text { Minimum } \\
\text { BMI }\end{array}$ & $\begin{array}{c}\text { Maximum } \\
\text { BMI }\end{array}$ & $\begin{array}{c}\text { Mean } \\
\text { BMI }\end{array}$ & $\begin{array}{c}\text { Standard } \\
\text { Deviation }\end{array}$ \\
\hline $\begin{array}{c}\text { Highest Minimum } \\
\text { Temp Group }\end{array}$ & 35 & 36 & 35.3 & 0.38 & 18.8 & 42.2 & 27.14 \\
$\begin{array}{c}\text { Lowest Minimum } \\
\text { Temp Group }\end{array}$ & 33.2 & 34 & 33.7 & 0.31 & 20.8 & 29.6 & 25.1 \\
\hline
\end{tabular}




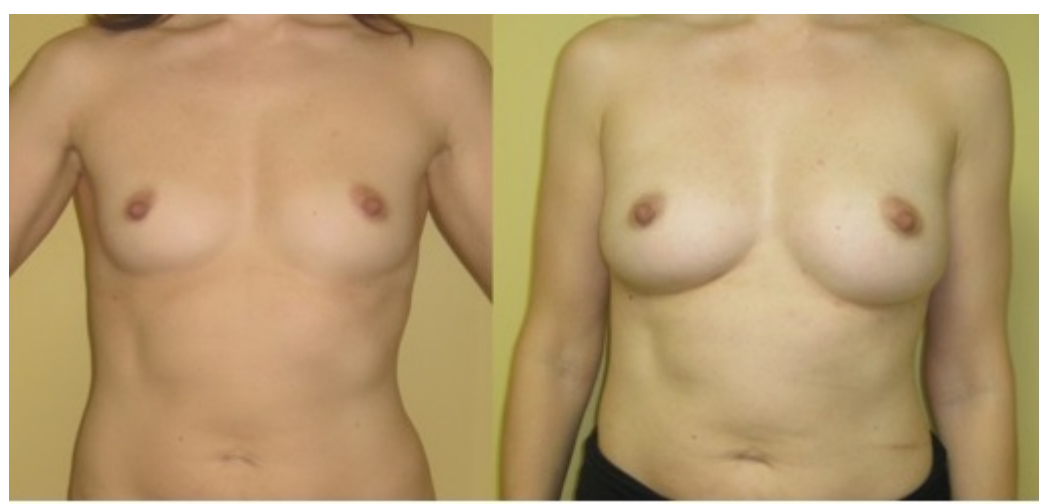

(a)

(b)

Figure 3. (a) Preoperative, and (b) one-year postoperative fat transplantation for breast augmentation.

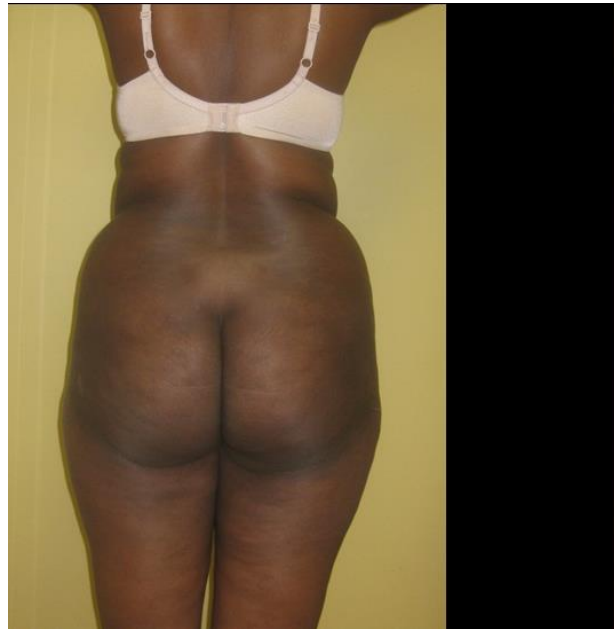

(a)

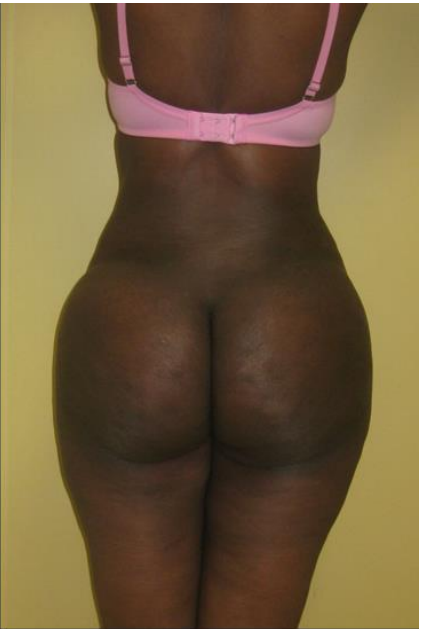

(b)

Figure 4. (a) Preoperative and (b) one-year postoperative fat transplantation for buttock augmentation.

\section{Discussion}

Patients who received autologous fat transplantation were satisfied with the outcome in $100 \%$ of our cases, which is consistent with the very positive satisfaction statistics found in the literature for this procedure mentioned previously.

Tumescent anesthesia has been successfully used in liposuction procedures since the 1980s, and was revolutionary in the sense that it greatly diminished the risk of serious adverse events from the procedure, including blood loss and significant fluid shifts. The technique involves local infusion of a saline solution containing lidocaine. This technique is often used alone in the setting of liposuction, but due to the fact that we are also performing fat transplantation, a combination of GA and tumescent anesthesia is required for our patients. In 1988, Klein demonstrated that tumescent anesthesia provides a relatively low risk of systemic lidocaine toxicity [12]. Despite improvements since the advent of tumescent anesthesia, liposuction is not an entirely benign procedure, and still carries some risk of fatality [13].

Lidocaine toxicity often presents with CNS or cardiovascular symptoms. A moderate or severe overdose can result initially in CNS excitation, in the form of seizures [14], an effect which can be masked by pre-treatment with benzodiazepines. Additionally, a later effect of CNS depression, characterized by respiration depression is also a significant risk. Since we perform our procedure under GA, with the patient intubated, the risk of death from this respiratory depression is somewhat mitigated. Also, due to its effect as a sodium channel blocker 
which is active on cardiac tissue, lidocaine toxicity can often present with reentrant arrhythmias, or diminished blood pressure and heart rate. Injecting lidocaine as a tumescent solution into fatty tissue does not appear to cause the same effects because of the relatively poor absorption of this solution into systemic circulation when administered in this manner. Klein reported doses of $35 \mathrm{mg} / \mathrm{kg}$ to be safe when used for liposuction [15], and Ostad later reported $55 \mathrm{mg} / \mathrm{kg}$ doses to also be safe in this setting [16]. Local anesthetic toxicity is a medical emergency requiring immediate treatment with first and foremost, an infusion of lipid emulsion, intralipid, which acts to significantly diminish the adverse effects of the agent [17]. Lipid emulsion has even been reported as effective in prolonged, intractable cardiac arrest secondary to lidocaine toxicity [18]. Though the exact mechanism of action of lipid emulsion in this setting is unknown, it has been proposed that it may act by decreasing circulating drug concentration or by acting as a myocardial energy source directly. Additionally, Benzodiazepines are effective for seizure control as is propofol, though it may potentiate cardiovascular effects. Continuous monitoring of the patient's cardiovascular status is essential, with IV fluids and boluses of epinephrine as needed. Amiodarone is the drug of choice for treatment of ventricular arrhythmias caused by local anesthetic toxicity [19]. Since our patients are intubated, we are able to aggressively manage the airway and prevent the effects of respiratory depression.

Preparation and surgeon administration of the tumescent solution must be very carefully performed. Martinez et al. report a 2008 fatality due to lidocaine toxicity in a patient receiving tumescent anesthesia for an elective liposuction procedure [20]. In that case, the death was found to be due to gross negligence, and as mentioned previously tumescent anesthesia is generally accompanied by a low risk of local anesthetic toxicity. Local anesthetic toxicity has been reported in numerous situations but is often related to inadvertent intravenous injection of the agent.

Proper management of our patients' temperature is an essential component of safe anesthesia. Though uncommon, there are case reports of patients who have become hypothermic under GA, and have subsequently suffered cardiovascular collapse. In one such case report, Nishikawa et al. describe a patient who suffers progressive hypothermia despite placement of a warming blanket and use of warm IVF; with the patient ultimately requiring continuous veno-venous hemofiltration $(\mathrm{CVVH})$ intraoperatively for rewarming [21]. Numerous studies and case reports have been written about surgical catastrophes secondary to patient positioning intra-operatively [22] [23]. Due to the numerous patient re-positioning during our procedures, the risk of this complication remains low, but it is important to remain vigilant due to the catastrophic nature of these injuries. Considering the elective nature of our procedures, it is imperative that we maintain the lowest possible intraoperative risk, and appropriate temperature management and positioning are therefore essential.

Another significant risk while injecting large volumes of adipose tissue is the possibility of fat embolism syndrome (FES). Most often FES is seen as a result of long-bone trauma, but it has also been reported secondary to both orthopedic surgery and liposuction [24]. Specifically, there have been case reports of FES during a number ORIF procedures and knee arthroplasty. When diagnosing FES, the most commonly cited and widely used system is Gurd and Wilson's criteria (major criteria: respiratory failure, cerebral dysfunction, and skin petechiae) [25]. Most often, the initial presenting symptoms of FES are those of respiratory distress, namely dyspnea and tachypnea. Intra-operatively, this respiratory distress may be manifested as a drop in oxygen saturation and decrease in end-tidal $\mathrm{CO}_{2}$. As many as $80 \%$ of patients with FES will also develop some neurological manifestations ranging from mild disorientation to seizure and coma, and about $50 \%$ of patients with FES will develop the classic petechial rash [26]. Due to the patient being asleep during most procedures where FES is a risk, it is essential to perform focused physical examinations looking for Gurd and Wilson's major/minor criteria, like the aforementioned rash, characteristic retinal changes, jaundice, and anuria/oliguria, whenever FES is suspected. When not fatal, FES is usually self limited, with the goal of treatment being to support and maintain arterial oxygen saturation via high-flow oxygen, PEEP in addition to volume resuscitation [27]. So far, all other treatments, including dextran, steroids, heparin and alcohol have been found ineffective to this point [28], though a recent case report by Sarkar et al. describes the successful management of massive intraoperative fat embolism with percutaneous cardiopulmonary support [29]. The mortality rate of patients with FES varies widely in the literature, with $5 \%-15 \%$ being commonly cited [30]; though it is often noted that more severe symptoms of respiratory distress are associated with a higher overall mortality rate. Though we did not have any occurrences of this adverse event, it remains an important consideration due to our use of liposuction and FES's very poor prognosis. 


\section{Conclusion}

Autologous fat transplantation for the purposes of breast and buttock augmentation is an emerging technique showing great promise, providing natural volume enhancement and leaving patients very satisfied with the result. This technique may be an ideal, safe solution for patients who want to have both liposuction and breast/buttock augmentation, but do not want the extra difficulty and risk of two separate procedures or artificial implants. Anesthesiologists, confronted with such otherwise healthy patients electing to undergo such cosmetic procedures, must be keenly aware of the potential pitfalls of hypothermia, lidocaine toxicity, and airway management during patient repositioning, and must work with the increasing number of surgeons beginning to perform such procedures.

\section{References}

[1] American Society of Plastic Surgeons (2012) American Society of Plastic Surgeons Report of the 2010 Plastic Surgery Statistics. www.plasticsurgery.org

[2] Gutowski, K.A. (2009) Current Applications and Safety of Autologous Fat Grafts: A Report of the ASPS Fat Graft Task Force. Plastic and Reconstructive Surgery, 124, 272-280. http://dx.doi.org/10.1097/PRS.0b013e3181a09506

[3] Nicareta, B., Pereira, L.H., Sterodimas, A. and Illouz, Y.G. (2011) Autologous Gluteal Lipograft. Aesthetic Plastic Surgery, 35, 216-224. http://dx.doi.org/10.1007/s00266-010-9590-y

[4] Rosing, J.H., Wong, G., Wong, M.S., Sahar, D., Stevenson, T.R. and Pu, L.L. (2011) Autologous Fat Grafting for Primary Breast Augmentation: A Systematic Review. Aesthetic Plastic Surgery, 35, 882-890. http://dx.doi.org/10.1007/s00266-011-9691-2

[5] Blanchard, J. (2011) Humidity, Temperatures, and Air Exchanges in the OR [Clinical Issues]. AORN Journal, 89, 11291131. http://dx.doi.org/10.1016/j.aorn.2009.05.012

[6] Fuzaylov, G. and Fidkowski, C.W. (2009) Anesthetic Considerations for Major Burn Injury Pediatric Patients. Pediatric Anesthesia, 19, 202-211. http://dx.doi.org/10.1111/j.1460-9592.2009.02924.X

[7] Klock Jr., P.A., Czeslick, E.G., Klafta, J.M., Ovassapian, A. and Moss, J. (2001) The Effect of Sevoflurane and Desflurane on Upper Airway Reactivity. Anesthesiology, 94, 963-967. http://dx.doi.org/10.1097/00000542-200106000-00008

[8] Rüsch, D., Eberhart, L.H., Wallenborn, J. and Kranke, P. (2010) Nausea and Vomiting after Surgery Under General Anesthesia an Evidence-Based Review Concerning Risk Assessment, Prevention, and Treatment. Deutsches Ärzteblatt International, 107, 733-741.

[9] Gan, T.J., Meyer, T.A., Apfel, C.C., Chung, F., Davis, P.J., Habib, A.S., Hooper, V.D., et al. (2007) Society for Ambulatory Anesthesia Guidelines for the Management of Postoperative Nausea and Vomiting. Anesthesia and Analgesia, 105, 1615-1628. http://dx.doi.org/10.1213/01.ane.0000295230.55439.f4

[10] Steely, R.L., Collins Jr., D.R., Cohen, B.E. and Bass, K. (2004) Postoperative Nausea and Vomiting in the Plastic Surgery Patient. Aesthetic Plastic Surgery, 28, 29-32. http://dx.doi.org/10.1007/s00266-004-3015-8

[11] Punjasawadong, Y., Boonjeungmonkol, N. and Pongchiewboon, A. (2007) Bispectral Index for Improving Anaesthetic Delivery and Postoperative Recovery. Cochrane Database Systematic Reviews, 17, Published Online.

[12] Klein, J.A. (1988) Anesthesia for Liposuction in Dermatologic Surgery. The Journal of Dermatologic Surgery and Oncology, 14, 1124-1132. http://dx.doi.org/10.1111/j.1524-4725.1988.tb03469.x

[13] Grazer, F.M. and de Jong, R.H. (2000) Fatal Outcomes from Liposuction: Census Survey of Cosmetic Surgeons. Plastic \& Reconstructive Surgery, 105, 436-446.

[14] Mehra, P., Caiazzo, A. and Maloney, P. (1998) Lidocaine Toxicity. AnesthProg, 45, 38-41.

[15] Klein, J.A. (1990) Tumescent Technique for Regional Anesthesia Permits Doses of $35 \mathrm{mg} / \mathrm{kg}$ for Liposuction. The Journal of Dermatologic Surgery and Oncology, 16, 248-263. http://dx.doi.org/10.1111/j.1524-4725.1990.tb03961.x

[16] Ostad, A., Kageyamam, N. and Moy, R.L. (1996) Tumescent Anesthesia with Lidocaine Dose of 55 mg/kg Is Safe for Liposuction. Journal of Dermatologic Surgery \& Oncology, 22, 921-927.

[17] Weinberg, G.L. (2012) Lipid Emulsion Infusion: Resuscitation for Local Anesthetic and Other Drug Overdose. Ansthesiology, 117, 180-187. http://dx.doi.org/10.1097/ALN.0b013e31825ad8de

[18] Dix, S.K., Rosner, G.F., Nayar, M., Harris, J.J., Guglin, M.E., Winterfield, J.R., Xiong, Z., et al. (2011) Intractable Cardiac Arrest Due to Lidocaine Toxicity Successfully Resuscitated with Lipid Emulsion. Critical Care Medicine, 39, 872-874. http://dx.doi.org/10.1097/CCM.0b013e318208eddf

[19] Neal, J.M., Bernards, C.M., Butterworth, J.F., Di Gregorio, G., Drasner, K., Hejtmanek, M.R., Mulroy, M.F., et al. 
(2010) ASRA Practice Advisory on Local Anesthetic Systemic Toxicity. Regional Anesthesia \& Pain Medicine, 35, 152-161. http://dx.doi.org/10.1097/AAP.0b013e3181d22fcd

[20] Martínez, M.A., Ballesteros, S., Segura, L.J. and García, M. (2008) Reporting a Fatality during Tumescent Liposuction. Forensic Science International, 178, e11-e16. http://dx.doi.org/10.1016/j.forsciint.2008.01.013

[21] Nishikawa, K., Kokita, N., Koshimizu, S., Itoh, T., Ichimiya, T. and Namiki, A. (1995) Cardiopulmonary Resuscitation with Continuous Veno-Venous Hemofiltration for Intraoperative Cardiac Arrest Owing to Hypothermia-A Case Report. Masui, 44, 1401-1405.

[22] Mattei, A., Di Pierro, G.B., Rafeld, V., Konrad, C., Beutler, J. and Danuser, H. (2013) Positioning Injury, Rhabdomyolysis and Serum Creatinine Kinase-Concentration Course in Patients Undergoing Robot-Assisted Radical Prostatectomy and Extended Pelvic Lymph Node Dissection. Journal of Endourology, 27, 45-51.

http://online.liebertpub.com/doi/abs/10.1089/end.2012.0169 http://dx.doi.org/10.1089/end.2012.0169

[23] Pillai, A.K., Ferral, H., Desai, S., Paruchuri, S., Asselmeier, S. and Perez-Gautrin, R. (2007) Brachial Plexus Injury Related to Patient Positioning. Journal of Vascular and Interventional Radiology, 18, 833-834. http://dx.doi.org/10.1016/j.jvir.2007.04.033

[24] Wang, H.D., Zheng, J.H., Deng, C.L., Liu, Q.Y. and Yang, S.L. (2008) Fat Embolism Syndromes Following Liposuction. Aesthetic Plastic Surgery, 32, 731-736. http://dx.doi.org/10.1007/s00266-008-9183-1

[25] Gurd, A.R. and Wilson, R.E. (1974) The FES. The Journal of Bone \& Joint Surgery, 56, 408-416.

[26] Laub Jr., D.R. and Laub, D.R. (1990) Fat Embolism Syndrome after Liposuction: A Case Report and Review of the Literature. Annals of Plastic Surger, 25, 48-52. http://dx.doi.org/10.1097/00000637-199007000-00011

[27] Shaikh, N. (2009) Emergency Management of Fat Embolism Syndrome. Journal of Emergencies Trauma and Shock, 2, 29-33. http://dx.doi.org/10.4103/0974-2700.44680

[28] Enneking, F.K. (1995) Cardiac Arrest during Total Knee Replacement. Journal of Clinical Anesthesia, 7, $253-263$. http://dx.doi.org/10.1016/0952-8180(94)00043-4

[29] Sarkar, S., Mandal, K. and Bhattacharya, P. (2008) Successful Management of Massive Intraoperative Pulmonary Fat Embolism with Percutaneous Cardiopulmonary Support. Indian Journal of Critical Care Medicine, 12, 136-139. http://dx.doi.org/10.4103/0972-5229.43684

[30] Fulde, G.W. and Harrison, P. (1991) Fat Embolism—A Review. Archives of Emergency Medicine, 8, $233-239$. http://dx.doi.org/10.1136/emj.8.4.233 
Scientific Research Publishing (SCIRP) is one of the largest Open Access journal publishers. It is currently publishing more than 200 open access, online, peer-reviewed journals covering a wide range of academic disciplines. SCIRP serves the worldwide academic communities and contributes to the progress and application of science with its publication.

Other selected journals from SCIRP are listed as below. Submit your manuscript to us via either submit@scirp.org or Online Submission Portal.
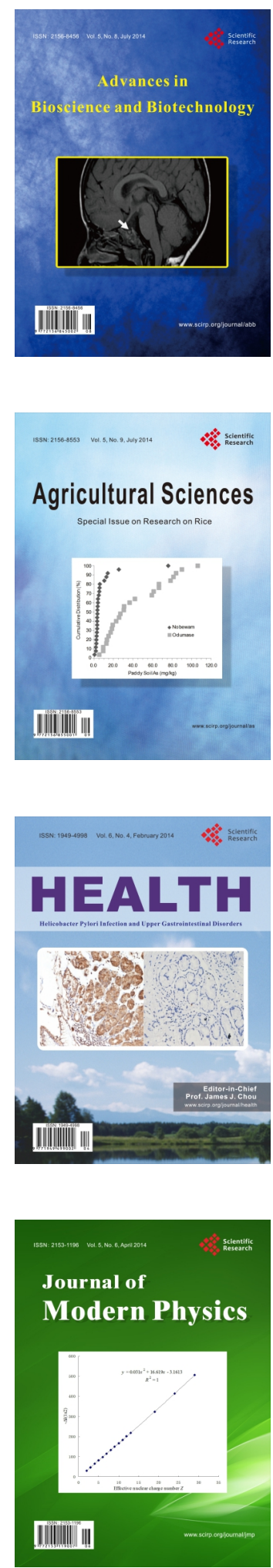
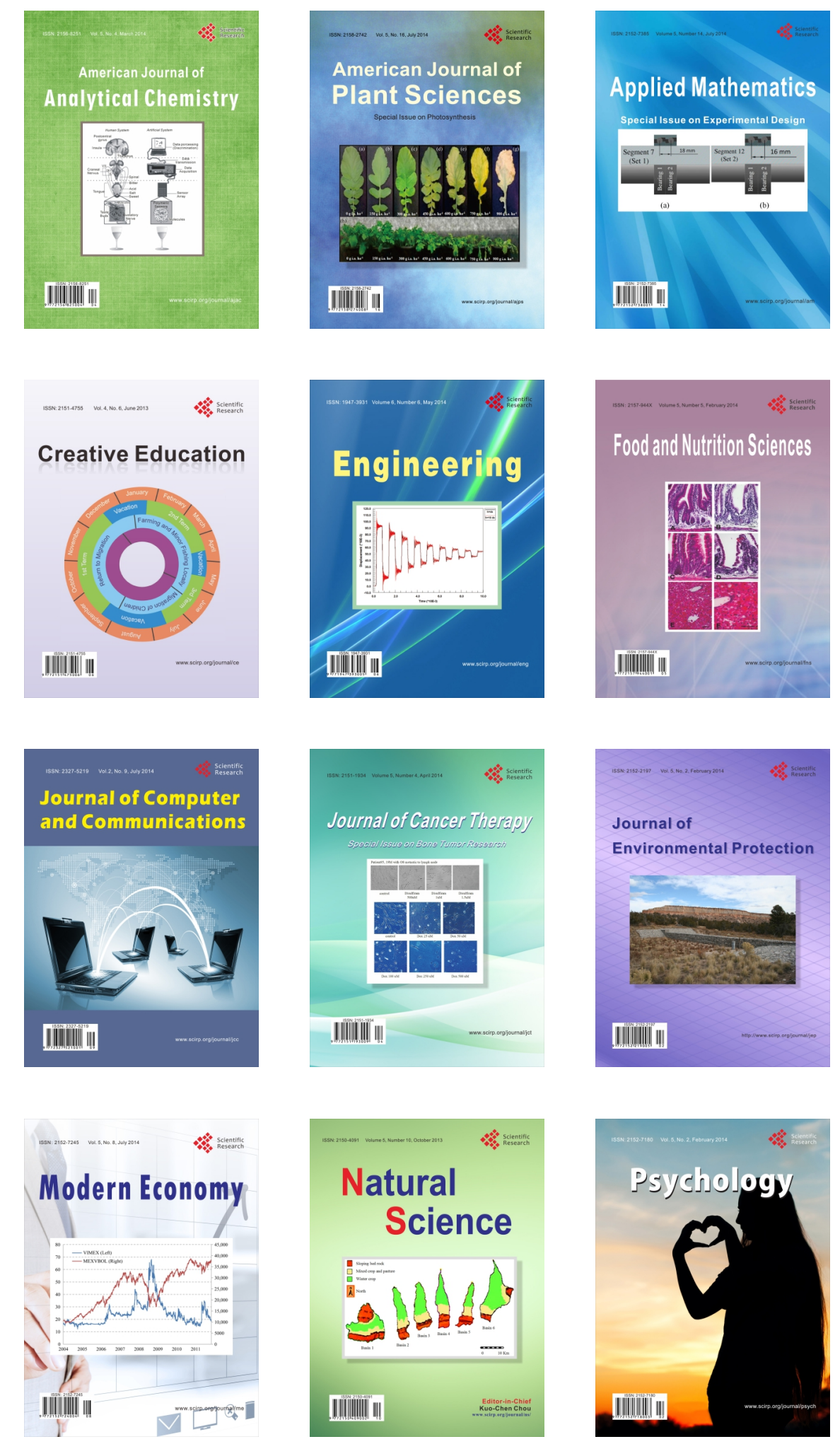